\title{
A felicidade de Narciso: reflexos do Eu perfeito na publicidade
}

\section{Hertz Wendel de Camargo ${ }^{1}$ Antonio Lemes Guerra Junior ${ }^{2}$}

Recibido: 2016-01-24

Enviado a pares: 2016-01-26
Aprobado por pares: 2016-02-10

Aceptado: 2016-04-27

DOI: 10.5294/pacla.2017.20.2.5

Para citar este artículo / to reference this article / para citar este artigo Camargo, H. W. y Guerra Junior, A. L. (2017). A felicidade de Narciso: reflexos do Eu perfeito na publicidade. Palabra Clave, 20(2), 389-410. DOI: 10.5294/pacla.2017.20.2.5

\section{Resumo}

Neste trabalho, propomos uma reflexão sobre a felicidade representada no discurso publicitário, enquanto resultado da satisfação propiciada pelo consumo. Para essa tarefa, concentramos nossa atenção no conteúdo apresentado pelo filme publicitário Narcisos, no qual confluem discursos, temas, imagens, em uma construção mítica da felicidade. As análises são empreendidas em segmentos distintos, mas complementares: são discutidos os caracteres míticos do discurso que embasa o texto audiovisual posto sob observação, considerando os aspectos ideológicos e psicossociais movimentados em sua construção; é enfatizado o sincretismo de linguagens selecionadas para a transmissão de sua mensagem máxima —a felicidade pela perfeição do $\mathrm{Eu}$-, evidenciando as relações intertextuais estabelecidas, bem como os efeitos argumentativos dos recursos linguísticos acionados. Nesse percurso, o resultado foi o efetivo diálogo entre teorias que, na sua heterogeneidade, embasam as considerações acerca da felicidade inscrita e incitada no/ pelo consumo.

\section{Palavras-chave}

Felicidade; mito; consumo; filme publicitário (Fonte: Tesauro da Unesco).

1 Universidade Federal do Paraná - UFPR. Brasil. hertzwendel@yahoo.com.br

2 Universidade Norte do Paraná - UNOPAR. Brasil. junior.guerra@hotmail.com 


\section{La felicidad de Narciso: reflejos del Yo perfecto en la publicidad}

\section{Resumen}

En este trabajo, proponemos una reflexión sobre la felicidad representada en el discurso publicitario, en cuanto al resultado de la satisfacción propiciada por el consumo. Para esta tarea, nos concentramos en el contenido presentado por la película publicitaria Narcisos, en la cual confluyen discursos, temas, imágenes, en una construcción mítica de la felicidad. Los análisis son emprendidos en segmentos distintos, pero complementarios: se discuten los caracteres míticos del discurso que es la base del texto audiovisual bajo observación, considerando los aspectos ideológicos y psicosociales que se mueven en su construcción; se hace énfasis en el sincretismo de lenguajes seleccionados para la transmisión de su mensaje máximo - la felicidad por la perfección del Yo-, evidenciando las relaciones intertextuales establecidas, así como los efectos argumentativos de los recursos lingüísticos accionados. En este recorrido, el resultado fue el efectivo diálogo entre teorías que, en su heterogeneidad, proporcionan el fundamento de las consideraciones acerca de la felicidad inscrita e incitada en/por el consumo.

\section{Palabras clave}

Felicidad; mito; consumo; película publicitaria (Fuente: Tesauro de la Unesco). 


\section{Narcissus's Happiness: Reflections of the Perfect Self in Advertising}

\section{Abstract}

In this paper, we propose a reflection on the happiness represented in the advertising discourse, in terms of the satisfaction afforded by consumption. For this purpose, we focus on the content presented by the advertising film Narcissus, in which discourses, themes and images converge in a mythical construction of happiness. The analyses are carried out in separate but complementary segments: the mythical nature of the discourse that lays the foundation of the audiovisual under observation is discussed, considering the ideological and psychosocial aspects involved in its construction; emphasis is made on the syncretism of languages selected for transmitting its greatest message- the happiness resulting from the perfection of the Self-, evidencing the intertextual relations established, as well as the argumentative effects of the linguistic resources involved. The result was the effective dialogue between theories that, in their heterogeneity, lay the foundations of the considerations on the happiness inscribed and encouraged in/by consumption.

\section{Keywords}

Happiness; myth; consumption; advertising film (Source: Unesco Thesaurus). 


\section{Introdução}

A felicidade, alvo de buscas constantes no universo do consumo, está intimamente ligada à satisfação, ao contentamento. $\mathrm{O}$ mito de Narciso materializa esse processo: a observação apaixonada de si mesmo, a contemplação do belo, do Eu perfeito, revela o estado de felicidade vivenciado por aquele que, ao consumir sua própria imagem, se satisfaz com o que vê. A mídia prega uma atuação narcísica: a ordem é enquadrar-se em padrões, assumir formas, mergulhar e fundir-se em imagens, transfigurar-se em exemplos de beleza e sofisticação. O espelho, figurativização máxima da autoimagem, assume nesse contexto o papel de um ambíguo ditador: atrai o belo, fascinao e torna-o feliz; repele o feio, exige dele transformação.

A antropologia visual e a antropologia do consumo são contribuições importantes para a abordagem dos enunciados publicitários. As representações do Eu remetem aos estudos da antropologia visual, dedicada à análise das representações do homem por meio das imagens, bem como aos processos de sua produção. Nesse sentido, a natureza mimética da publicidade opera constantemente com semelhanças, sintonias, empatias, simulacros de discursos e situações muito próximos à realidade ou ao perfil do consumidor-alvo.

Para a antropologia do consumo, a publicidade figura como importante campo para a interpretação da cultura, dos sujeitos e dos grupos humanos. Para Rocha (2006), a publicidade é “[...] a narrativa que dá sentido ao consumo e está, seguramente, entre as principais produtoras de sistemas simbólicos presentes em nosso tempo" (p. 12). A publicidade estrutura o sistema da mídia, mantém vivos os mitos, magias e rituais do cotidiano nas cidades e nas práticas sociais contemporâneas. A publicidade protagoniza uma narrativa que traduz o Eu em alteridade e, durante sua recepção, ocorre um processo de objetificação do sujeito em discurso publicitário que, antes de estimular o consumo de bens e serviços, é consumido.

Portanto, os conceitos de Baitello Junior (2005) sobre iconofagia representam um ponto de encontro entre a antropologia visual e a antropologia do consumo, visto que, atualmente, vivenciamos o terceiro estágio de 
devoração —as imagens devoradoras do homem — verificado, especialmente, no consumo de imagens publicitárias. Segundo o autor, existem três etapas da iconofagia: "[...] na primeira, imagens devoram imagens; na segunda etapa, homens devoram imagens; e a última, imagens devoram os homens" (Baitello Junior, 2005, p. 53-55).

Neste texto, propomos uma reflexão sobre a felicidade representada no discurso publicitário, enquanto resultado da satisfação propiciada pelo consumo. Para essa tarefa, concentramos nossa atenção no conteúdo apresentado pelo filme publicitário $\mathrm{Narcisos}^{3}$, no qual confluem discursos, temas, imagens, em uma construção mítica da felicidade.

As análises são empreendidas em segmentos distintos, mas complementares: são discutidos os caracteres míticos do discurso que embasa o texto audiovisual posto sob observação, considerando os aspectos ideológicos e psicossociais movimentados em sua construção; é enfatizado o sincretismo de linguagens selecionadas para a transmissão de sua mensagem máxima —a felicidade pela perfeição do $\mathrm{Eu}$ 一, evidenciando as relações intertextuais estabelecidas, bem como os efeitos argumentativos dos recursos linguísticos acionados. Nesse percurso, esperamos efetivar o diálogo entre teorias que, na sua heterogeneidade, embasem as considerações acerca da felicidade inscrita e incitada no/pelo consumo. Para tanto, empreendemos uma análise discursiva (visual e verbal) do filme publicitário Narcisos que, apesar de produzido em 2011, ainda é um emblemático exemplo de enunciado midiático que proporciona uma leitura plausível da nossa atual condição cultural.

\section{Narciso e o consumo de si mesmo}

O mito grego de Narciso, conforme Kury (2008, p. 278), pode ser assim resumido: Filho do deus do rio Céfiso e da ninfa Liríope, Narciso nasceu com uma beleza incomum. Preocupada com a beleza da criança, que não deveria ser igual nem maior que a dos deuses, sua mãe consulta o vidente Tirésias para saber qual seria o destino do filho. Ele teria uma longa vida,

3 Disponível em: https://www.youtube.com/watch?v=3dB9kIhEgSM 
respondeu o oráculo, mas apenas se ele nunca olhasse para a própria face. Quando adulto, muitas moças e ninfas apaixonaram-se por Narciso, porém o belo jovem não se interessava por ninguém. A ninfa Eco, uma das mais apaixonadas, não se conformou com o desprezo de Narciso e afastou-se amargurada para um lugar deserto, onde definhou até que somente restaram dela os lamentos. As moças e as ninfas desprezadas rogaram aos deuses para vingá-las. A deusa Nêmesis apiedou-se delas e induziu Narciso, depois de uma caçada, em um dia muito quente, a debruçar-se à beira de um lago para beber água. Nesse instante, ao olhar a própria face, no espelho d'água, apaixona-se morbidamente pela imagem, sem ter ciência que era a si mesmo que contemplava. Narciso, então, permaneceu imóvel em contemplação ininterrupta de sua face refletida. Debilitado, morreu.

Conforme Tap (1996, p. 20), o mito de Narciso evidencia três marcadores simbólicos:

- a imagem especular - imagem virtual em espelho (speculum = espelho) e amor de si mesmo;

- imagem gemelar - imagens de si e do outro, confundidas em um amor-identificatórico recíproco (o outro percebido como um gêmeo, idêntico a si);

- a palavra do outro, a repetir, quando se é privado de palavra pessoal (de desejo?) e dispersado aos ventos (dispersão interna e externa).

Permeado, então, por simbologias, "o narcisismo como amor a si mesmo, fascinação a respeito da sua própria imagem, inscreve-se, de facto, num sistema diversificado de relações, de interditos e de significações" (Tap, 1996, p. 20). A contemplação do Eu, o desejo por si mesmo, a satisfação decorrente da identificação de si mesmo como um objeto de desejo propicia reflexões acerca do que move as pessoas em busca da felicidade, nesse caso alcançada no "estar bem consigo".

Para Noé (2002, p. 43), “Estudar Narciso é estudar o ser humano!”. Segundo o autor, na atualidade, o narcisismo configuraria um "mal-estar da civilização global”, isso porque circula pelos corredores sociais o "Homo nar- 
cissicus", em sua incessante busca pela satisfação quanto à sua imagem, moldada às margens de uma ditadura do ser belo. Nesse aspecto, "[...] o triunfo do narcisismo é correlato à difusão de um novo mito cultural, social, político e econômico: a fantasia de que cada um é especial e que pode realizar o que quer, desde que seja persistente na busca de concretização de seus objetivos" (Noé, 2002, p. 49).

As contemporâneas ideias de "ser e fazer o que quiser" atribuem ao ser humano certos caracteres que o aproximam de um deus. Lowen (1989) sintetiza isso: "Posso qualquer coisa (onipotência); (2) Sou visível em toda parte (onipresença); (3) Eu sei tudo (onisciência); e (4) Existo para ser adorado" (p. 111). A adoração, que satisfaz, é a base do narcisismo. O culto à própria imagem coloca o indivíduo em uma complexa situação: adora o outro, que não é o outro, mas o si mesmo, e a satisfação toma forma.

O que se deve ressaltar é, no entanto, a ambivalência do narcisismo, que se desfia em uma linha tênue entre o benigno e o maligno. Conforme aponta Noé (2002), o problema não é o narcisismo em si, mas o modo como se estabelece a relação entre as pessoas e a contemplação de suas imagens: "O mal-estar da nossa civilização hodierna global é tornar as pessoas reféns de seu narcisismo. Assim ele adquire características de uma patologia, porque a pessoa torna-se escrava de uma ilusão" (p. 56).

Desse modo, questionamos: a perfeição (observada na contemplação do Eu), a satisfação e a felicidade (decorrentes dessa contemplação) seriam, também, uma ilusão?

\section{Perfeição, satisfação e felicidade: nossa metodologia de análise}

Criado pela agência brasileira de publicidade F/Nazca, o filme Narcisos (com duração de 60 segundos, 28 planos e 11 sequências) foi lançado, em fevereiro de 2011, como parte da campanha institucional desenvolvida para a Honda, indústria de origem japonesa, que produz, no Brasil, motocicletas (desde 1974) e automóveis (desde 1997). Conforme o site da agência, o filme comemora a satisfação dos consumidores com os carros dessa marca, 
relatada na pesquisa “Os Eleitos 2010”, promovida anualmente pela revista Quatro Rodas, da Editora Abril. No filme, "vemos pessoas felizes e orgulhosas dentro do New Civic e New Fit, olhando para os próprios reflexos dentro dos carros" (F/Nazca, 2011).

Figura 1. Cena final e síntese da proposta do filme - a contemplação da autoimagem - acompanhada da frase do locutor: "-É o que acontece quando se tem os proprietários mais satisfeitos do país"

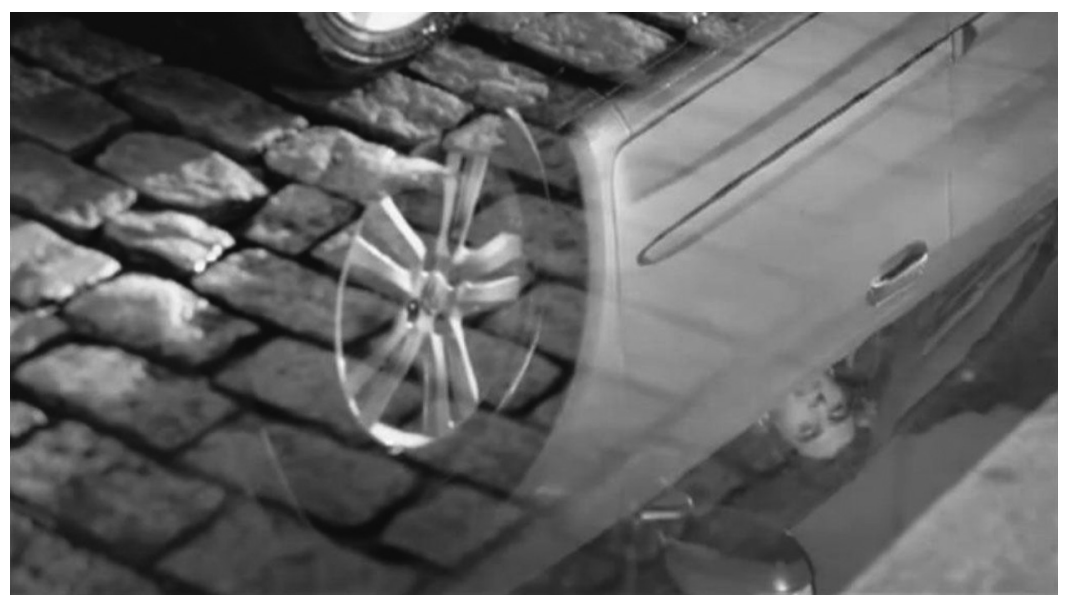

Fonte: frame do filme Narcisos (F/Nazca, 2011).

Como no mito, o roteiro do filme gira em torno do olhar a si mesmo. Não é apenas um olhar em que cada personagem se identifica pelo reflexo e, assim, afirma sua existência física no mundo; é um olhar que vai além, buscando o que está por baixo da expressão de felicidade e orgulho.

No final do filme, o locutor informa que a Honda foi a campeã da pesquisa "Os Eleitos 2010", e o New Civic, o "eleito dos eleitos". No filme, corpo e máquina — sujeito e objeto — se misturam, e a perfeição almejada para o produto está representada na perfeição física —a beleza facial dos modelos que interpretam os modernos Narcisos e a beleza da máquina que, "viva", também se "admira" nos reflexos-. Esse ser híbrido que nasce da fusão homem/automóvel é o ser contemplativo que vivencia o êxtase hedônico por sua própria imagem. Isso permite entrever a transferência de va- 
lores humanos para o objeto, em outras palavras, a antropomorfização do produto. Em determinado momento do filme, esquecemos que, por trás do carro, há um motorista, e o carro passa a ter vida própria; ele é quem se olha, contempla-se, deseja-se por meio dos diversos reflexos. O carro passa a ser a imagem idealizada, perfeita e singular do consumidor, que, em sua casa, se torna espectador do filme publicitário consumido por meio da televisão. Antropomorfizado, o produto passa a ser a imagem e a representação de quem o consome.

Nas entrelinhas do discurso, o filme conduz o espectador a imaginar que somente o carro da Honda pode levá-lo a ser um "eleito dos eleitos", outra forma de dizer "o melhor entre os melhores". Tal qual um espelho, a tela da televisão torna-se o reflexo do espectador, ele se vê naquele mundo, naquela realidade fantástica que transcorre diante dos seus olhos. Em narrativa audiovisual, o filme é o mito reatualizado. O locutor completa afirmando: "é o que acontece quando se tem os proprietários mais satisfeitos do país", como uma referência direta à pesquisa, mas, na verdade, refere-se às imagens do filme, como a dizer: "conforme você acaba de ver nas imagens, é o que acontece quando você possui um Honda”. Trata-se do êxtase consigo mesmo, o momento de contemplação do ego, o prazer de amar o carro como amar a si mesmo.

\section{Quadro 1. Texto da locução}

\begin{tabular}{|c|c|}
\hline Tempo & Locução \\
\hline Aos 45” do filme & - A Honda foi a campeã da pesquisa "Os Eleitos 2010". O New Civic, o eleito \\
dos eleitos.
\end{tabular}

Fonte: locução do filme Narcisos (F/Nazca, 2011).

A satisfação, apregoada pelo locutor do filme e com a qual os personagens se deparam em vários reflexos, ganha contornos de uma autoadmiração hedônica, isto é, os personagens sentem prazer no que veem. A canção do filme, em inglês, funciona como a voz dos pensamentos dos personagens, mas, por transferência, também se torna a voz dos pensamentos do espectador. "Amar a si mesmo não é pecado, o que você vê está certo, a imagem 
mostra sempre a verdade" - essa é a essência do jingle (canção) adaptada da seguinte maneira:

0 que você sente quando você para durante 0 dia... 0 que você diz quando você olha para o seu próprio passo, que mantém a mesma forma, e seu reflexo mostra que esse é o caminho certo... Tudo bem! Você sabe como mover-se lentamente para aproveitar cada momento como um menino? Vamos brincar! Não se preocupe, o seu reflexo mostra... esse é o caminho certo. Tudo bem! Tenha em mente que 0 seu reflexo mostra o caminho... Tenha em mente que a felicidade leva tempo mesmo... ${ }^{4}$

Discursivamente falando, a letra da canção é recoberta de marcas que a tornam altamente persuasiva. Inicialmente, o que mais chama a atenção é o insistente estabelecimento de contato entre anunciante e consumidor, este último recorrentemente evocado: é para "você" que as informações são direcionadas. Todo texto publicitário dirige-se para a segunda pessoa (você). Impossível entrarmos em contato com a publicidade sem estarmos na posição de receptores. Essa nossa condição ratifica a natureza da publicidade, que sempre chama para si o nosso olhar, porque sempre se dirige para nós, enunciatários. Os enunciados publicitários simulam a coloquialidade de uma conversa e dão alma à marca, humanizam-na, como se marca e produto, de fato, fossem vivos. "Você" é o centro da conversa. "Você" é o alvo dos interesses da marca, e a publicidade é o canal.

O elemento "cotidiano" também está presente, seja no momento em que "você para durante o dia", seja nos momentos da vida, nas brincadeiras, que devem ser aproveitados "como um menino", sem maiores preocupações. Essa aparente simplicidade é colocada em oposição ao requinte do produto, o automóvel, que se desdobra em reflexos carregados de convites à contemplação, ao desejo, à adoração.

Adicionalmente, é criado um campo semântico intimamente relacionado à transposição de distâncias, que caracterizam primariamente o

4 Letra original: What you feel when you stop during the day... / What you say when you look at your own pace and this place keeps the shape, and your reflection shows you that's the right way... / It's ok! / Do you know how to move slowly to enjoy every moment like a boy? / Let's play! / Don't worry, your reflection shows you ... that's the right way. / It's ok! / Keep in mind that your reflection shows the way... / Keep in mind that happiness takes time anyway... (Narcisos, F/Nazca, 2011). 
produto (o veículo): o "caminho". Nesse contexto, certas escolhas lexicais definem a trajetória narcisista dos possíveis consumidores.

\section{Quadro 2. Escolhas lexicais e sentidos possíveis do jingle}

\begin{tabular}{|c|c|c|}
\hline Substantivos & Verbos & Expressão \\
\hline $\begin{array}{l}\text { "Caminho": expressão máxima do } \\
\text { percurso traçado na busca de si mesmo, } \\
\text { na busca da imagem perfeita do Eu, na } \\
\text { trajetória do herói. } \\
\text { "Passo": representação das marcas } \\
\text { deixadas ao longo desse percurso. } \\
\text { A ideia de regularidade/perfeição } \\
\text { deve aqui ser resgatada: na canção, } \\
\text { o passo "mantém a mesma forma", } \\
\text { mostra o "caminho certo", mantém uma } \\
\text { regularidade nas escolhas e no desejo. }\end{array}$ & $\begin{array}{l}\text { "Parar": parar durante o dia a fim de olhar o } \\
\text { próprio passo, encontrando nele o caminho } \\
\text { certo, constitui uma releitura do momento } \\
\text { de estagnação temporal de Narciso, que para, } \\
\text { olha a própria imagem e vê nela a perfeição. } \\
\text { "Mover-se": modalizada pelo advérbio } \\
\text { "lentamente", a ação de mover-se expressa } \\
\text { a prescindibilidade da pressa, da agilidade, } \\
\text { uma vez que a contemplação exige tempo, } \\
\text { exige parada, um mergulho no tempo } \\
\text { mágico do Eu. }\end{array}$ & $\begin{array}{l}\text { "Levar tempo": relacionada } \\
\text { diretamente à felicidade, que } \\
\text { leva tempo para ser alcançada; } \\
\text { segundo a canção, a expressão } \\
\text { deixa-se relacionar, também, } \\
\text { à ideia de contemplação: o } \\
\text { consumidor, narcisisticamente, } \\
\text { deve desprender-se de amarras } \\
\text { temporais, parar no tempo, } \\
\text { contemplar a si mesmo, para } \\
\text { enxergar a perfeição e, assim, } \\
\text { serfeliz. }\end{array}$ \\
\hline
\end{tabular}

Fonte: elaborado pelos autores.

A contemplação do perfeito também é verificada nos personagens do filme, que admiram uma imagem do seu Eu ideal. Então, podemos entender o filme publicitário como imagem metafísica, mítica. No filme, o instante do encontro entre o sujeito e o seu duplo (sua imagem) representa um tempo em suspensão, sagrado, cujo objeto de desejo — de contemplação e satisfação- é o próprio Eu. Trata-se do instante em que Narciso, no mito grego, descobre-se e apaixona-se por sua própria beleza. Somos nós, espectadores, narcisos do mundo real a contemplar as imagens da publicidade por meio da televisão. Por outro lado,

Narciso pode ser também considerado como aquele que mata a verdade de si mesmo (sua realidade como indivíduo concreto) e morre em sua própria imagem, o seu duplo. [...] 0 aparecimento do duplo (a imagem de si mesmo) desafia o real do sujeito (a unicidade, a singularidade, a originalidade) a existir, afastando-o de sua verdade, arrastando-o para o jogo ilusório das aparências. (Sodré, 1994, p. 17)

Sujeito e objeto misturam-se, corpo e carro passam a ser um só, encontram-se nos vários reflexos. Ao encontrar seu duplo — a imagem do Eu nunca antes visto-, tudo ao redor parece ficar mais lento, e o carro-homem 
para o tempo, desliza lentamente ou volta para ver-se na fachada espelhada (Figura 2); passa lentamente diante de um espelho (Figura 3); hesita ultrapassar um caminhão cromado para nele admirar-se por mais tempo (Figura 4 ); em outra cena, literalmente, mergulha em si mesmo, imagem e sujeito se fundem ou mergulham um para dentro do outro (Figura 5).

Figura 2. Contemplação do Eu na fachada espelhada

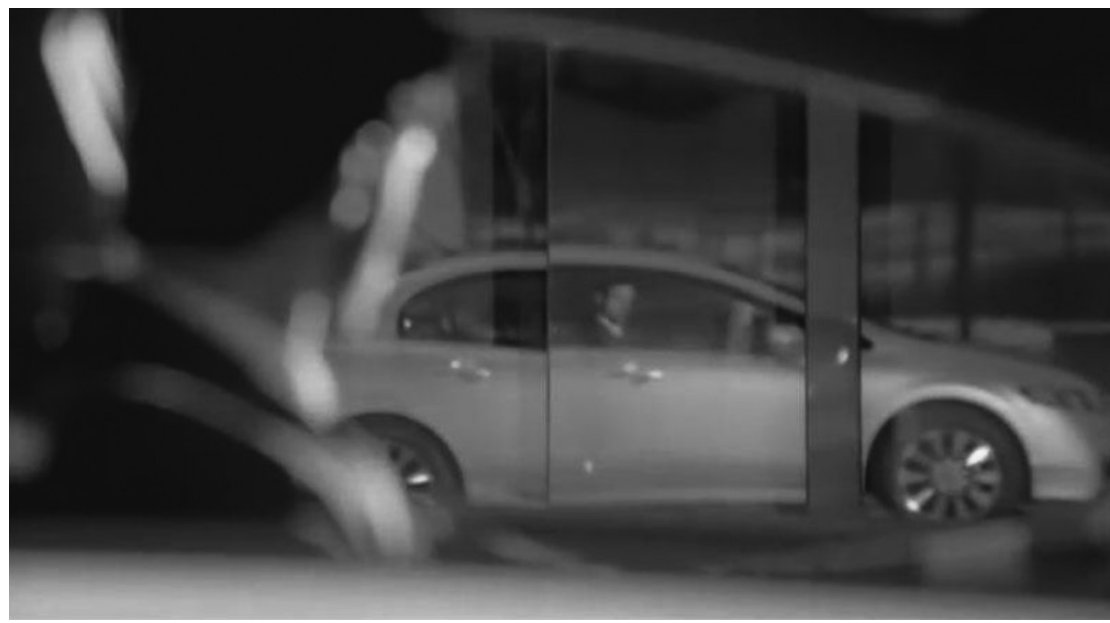

Fonte: frame do filme Narcisos (F/Nazca, 2011).

Figura 3. Contemplação do Eu no espelho

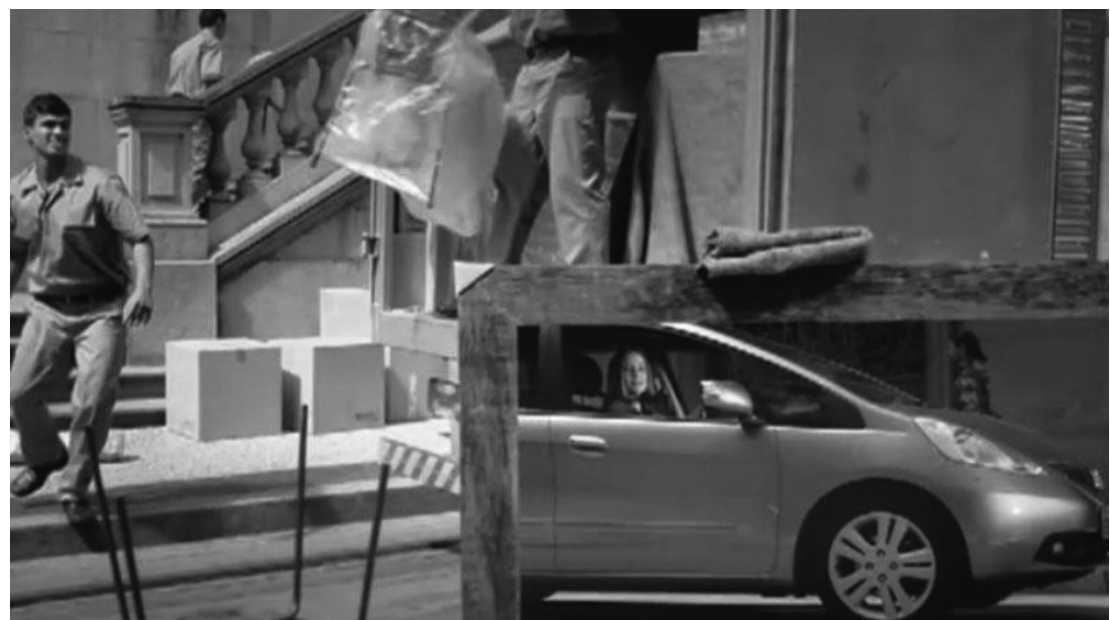

Fonte: frame do filme Narcisos (F/Nazca, 2011). 


\section{Figura 4. Contemplação do Eu na estrutura cromada do caminhão}

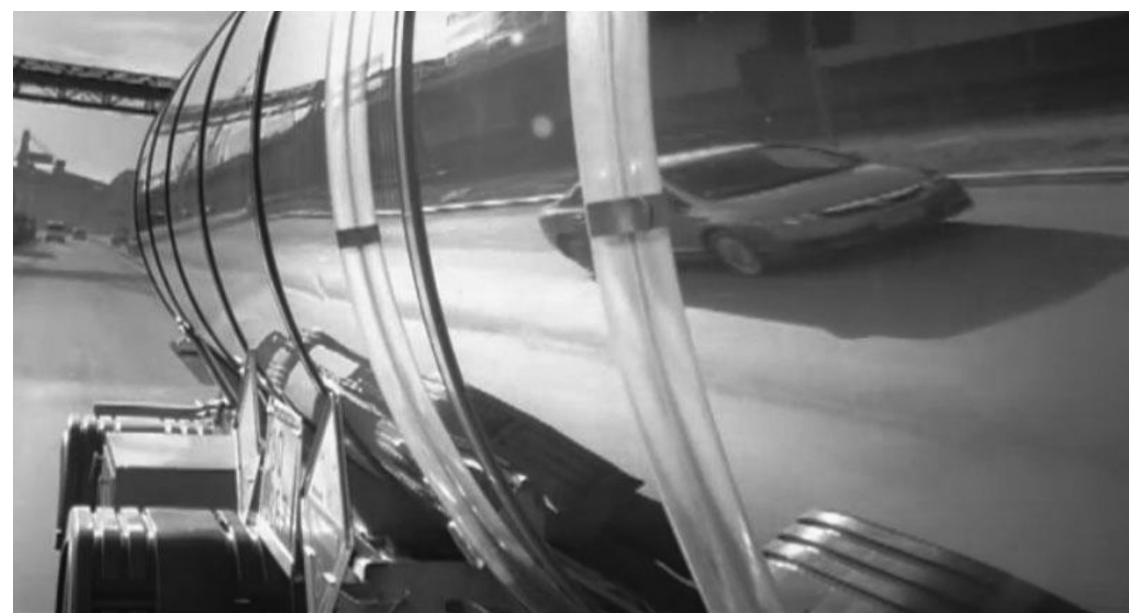

Fonte: frame do filme Narcisos (F/Nazca, 2011).

Figura 5. Fusão de imagens - sujeito e reflexo

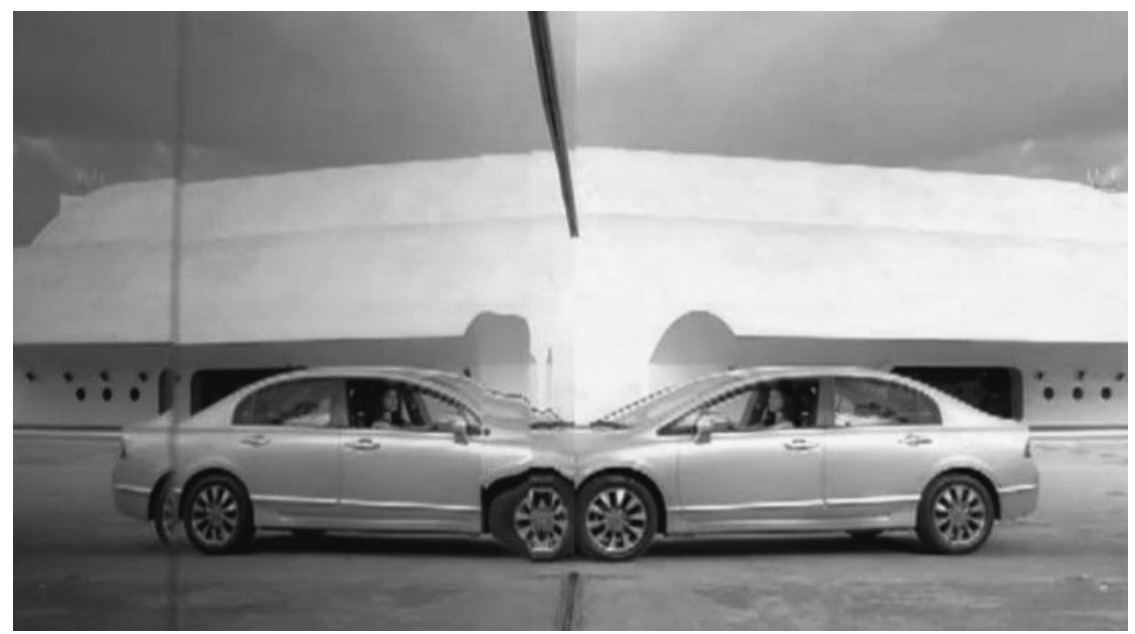

Fonte: frame do filme Narcisos (F/Nazca, 2011).

Essa sequência de imagens, além de outras verificadas no filme, com as mesmas características, em especial a exaltação da imagem refletida e contemplada, em virtude de certa regularidade, permite discutirmos a construção do anúncio sobre os pilares sustentadores da intertextualidade que, segundo Koch (1998), é "condição de existência do discurso" (p.47). 
Cada texto remete a ideias previamente apresentadas, em um processo ilimitado de resgate, de retomada, o que exclui a neutralidade, a pureza, de toda e qualquer produção discursiva. Isso é confirmado por Kristeva, uma das idealizadoras do conceito de intertextualidade, juntamente com Bakhtin, na década de 1960; para a autora, "todo texto se constrói como um mosaico de citações, todo texto é absorção e transformação de textos" (Kristeva, 2005, p. 68).

Blikstein (2008) salienta que a intertextualidade constitui "um processo por meio do qual um primeiro texto pode servir de referência para a geração de outros textos que, por sua vez, gerarão outros textos, possibilitando um vai-e-vem e um entrecruzamento [...]”. Desse modo, o conceito de intertextualidade evidencia o diálogo estabelecido entre discursos produzidos em momentos distintos, mas que carregam marcas em comum, capazes de tornar um deles uma espécie de repetição de seu precursor.

Se, diante dessas afirmações, considerarmos o filme publicitário enquanto uma manifestação textual, podemos afirmar que é também ele uma produção que se pauta no resgate de informações previamente disseminadas, ou seja, o resultado de um jogo intertextual, que emana indícios capazes de levar o leitor, no caso, o espectador, a relacioná-lo a conteúdos com os quais já teve contato.

De acordo com Koch e Travaglia (2003), "a intertextualidade pode ser de forma ou de conteúdo" (p. 92). A primeira delas ocorre "quando o produtor de um texto repete expressões, enunciados ou trechos de outros textos, ou então o estilo de determinado autor ou de determinados gêneros de discurso" (p. 92). Quanto à intertextualidade de conteúdo, esta "é uma constante: os textos de uma mesma época, de uma mesma área de conhecimento, de uma mesma cultura, etc., dialogam, necessariamente, uns com os outros" (p. 94).

A questão da temporalidade, no entanto, não é determinante para que se configure a intertextualidade, isto é, textos de todas as épocas podem ser evocados, relidos, reiterados, atualizados em novas vozes. O seu reconhe- 
cimento, porém, é crucial para que a intertextualidade seja percebida, uma vez que, em muitos casos, esse processo ocorre de modo implícito, não havendo uma indicação clara do texto "consultado". Isso pode prejudicar a compreensão, pois, como afirmam Koch e Travaglia (2003), "o reconhecimento do texto-fonte e dos motivos de sua representação, no caso da intertextualidade implícita, é [...] de grande importância para a construção do sentido de um texto" (p. 97).

Essa dependência de retomada de textos anteriores para o entendimento de um texto produzido em um momento posterior é comentada, também, por Costa Val (1999), quando a autora afirma que "inúmeros textos só fazem sentido quando entendidos em relação a outros textos, que funcionam como seu contexto" (p. 15, grifos no original).

Deve-se levar em consideração, ainda, que resgatar um texto anterior só se faz possível por meio de um tipo específico de conhecimento, o "conhecimento de mundo". Como arguem Koch e Travaglia (2005), "o estabelecimento do sentido de um texto depende em grande parte do conhecimento de mundo de seus usuários, porque é só este conhecimento que vai permitir a realização de processos cruciais para a compreensão" (p. 60, grifo no original), dentre os quais podem ser citados o reconhecimento de formas e/ou conteúdos parecidos nas duas produções: o texto e o intertexto.

Em se tratando do filme Narcisos, da Honda, o estabelecimento de um profícuo diálogo entre ele e o mito grego de Narciso dependerá do nível de conhecimento dos espectadores: enquanto, para uns, a remissão à trágica história do belo que se apaixona por si mesmo é claramente percebida, para outros, o filme pode não passar de mais uma criação publicitária qualquer, mais uma "ideia esquisita de publicitários". Camargo (2013) já tinha destacado a carga genealógica mítica das narrativas publicitárias.

O fato é que a intertextualidade está presente de forma indiscutível em Narcisos, seja em forma, seja em conteúdo. Em termos de conteúdo, a relação intertextual com o mito grego já começa pelo título do filme, sendo reiterado por meio das histórias e dos caminhos cotidianos dos consumidores 
satisfeitos, os contempladores/consumidores de autoimagens no século XXI. Já em termos de forma, em praticamente todas as cenas, incluindo as que aparecem nas imagens apresentadas há pouco, são percebidos resquícios da representação clássica de Narciso, como sugere a obra de Caravaggio.

\section{Figura 6. Narciso (1597-99), por Caravaggio}

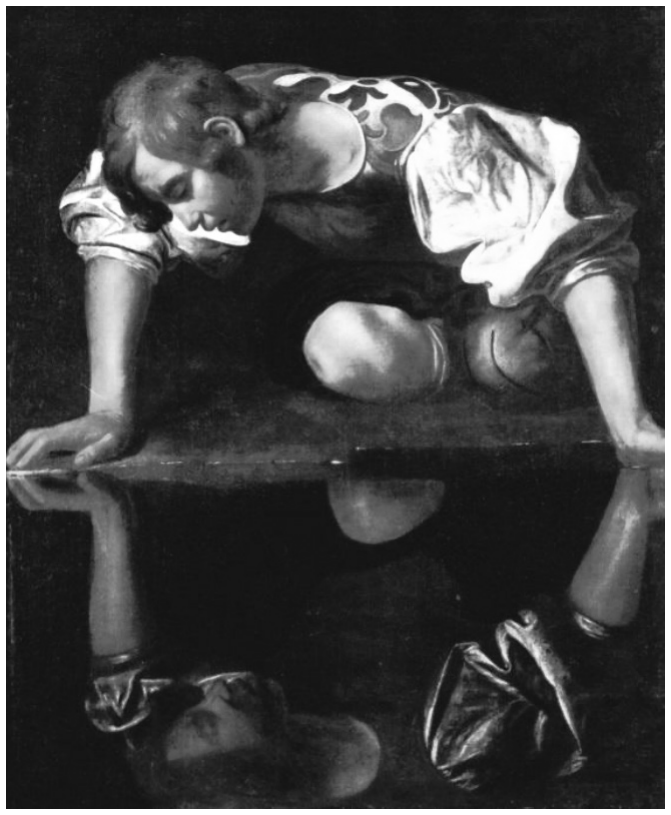

Fonte: TotallyHistory (2016).

Nessa representação imagética do mito, reproduzida ao longo dos séculos, com poucas variações, percebemos três elementos constituintes básicos: o sujeito contemplador (Narciso); o objeto de desejo (o reflexo no espelho d'água) e o confronto simétrico entre sujeito e objeto (a contemplação em si, o quase contato entre ambos, separados pelos limites de um espaço real e um espaço virtual). No filme publicitário da Honda, a mesma configuração se repete em todas as cenas, sendo a figurativização máxima percebida no caso a seguir (Figura 7), a cena final, em que os três caracteres são evidenciados: o sujeito contemplador (o automóvel/o consumidor); o objeto de desejo (o reflexo projetado em uma poça, na rua, à beira da calçada) e a repetição da simetria no confronto/quase contato entre sujeito e objeto. 
Figura 7. Início de enquadramento da cena final

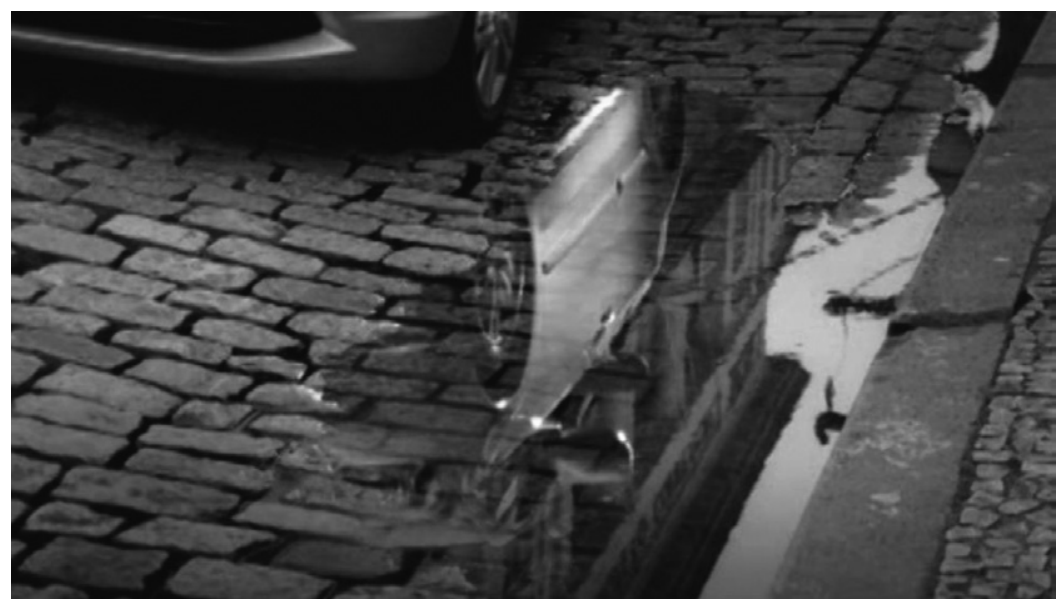

Fonte: frame do filme Narcisos (F/Nazca, 2011).

A comparação entre as regularidades intertextuais das duas imagens podem ser mais bem observadas no esquema comparativo a seguir.

Figura 8. Regularidades intertextuais

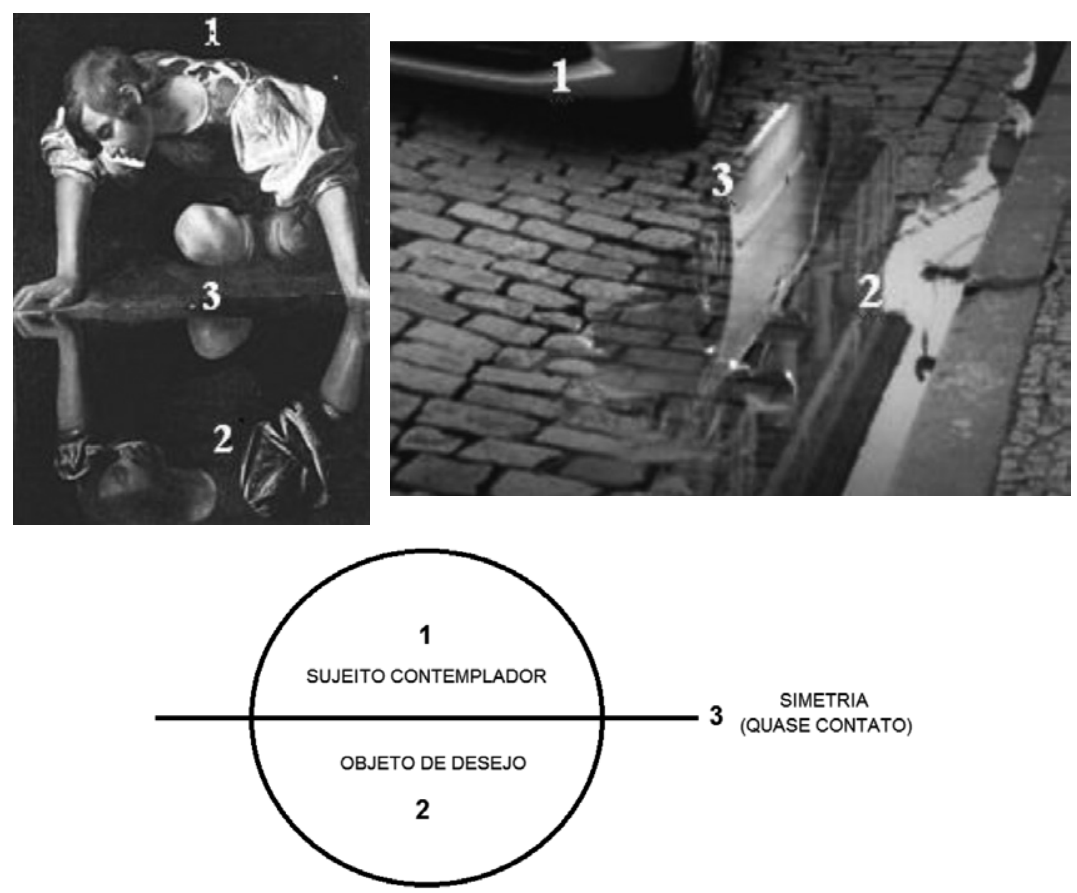

Fonte: elaborado pelos autores. 
No esquema comparativo, é possível evidenciar as regularidades e, mais que isso, o jogo intertextual entre as imagens. Embora, na pintura de Caravaggio, a contemplação do Eu ocorra em um movimento descendente vertical, na cena do filme o mesmo processo se dá em um direcionamento descendente diagonal. No entanto, a relação sequencial estabelecida entre os três elementos permanece inalterada. Vale frisar que é nesse quase contato que se instaura a satisfação do sujeito contemplador, a partir da qual ele alcança a felicidade.

Por meio do reflexo, os personagens se dão conta de que ocupam um lugar no mundo e isolam-se, como Narciso, ensimesmado em sua paixão, em seu mundo particular. No filme, os personagens se encasulam em seu carro. Em nenhuma cena, os personagens surgem dividindo o automóvel com outra pessoa; encontram-se solitários e, ao mesmo tempo, em companhia do produto repleto de "alma". O automóvel representa um espaço singular, território de quem dirige, espaço do Narciso consumidor.

O carro, como mercadoria-fetiche, carrega forte conotação de liberdade e potência individuais e torna-se extensão do corpo do seu usuário. Sem o carro, o Eu poderia deixar de existir, o prazer do olhar poderia esvairse. Sem o aparato, o Eu estaria desnudado da fantasia, mortal, real diante do espelho. As conexões estabelecidas são narcísicas; portanto, hedônicas e de poder, pois esse entrelaçamento entre o sujeito e o objeto (e a imagem) é capaz de suspender o tempo. É a partir da descoberta do outro-eu que a imagem passa a ter maior importância que o Eu original, o Eu real. Em plena cultura do individualismo, da independência pessoal e da liberdade (como valores dominantes), vive-se uma espécie de mais-alienação, de rendição absoluta ao brilho não exatamente dos objetos, mas da imagem dos objetos (Bucci e Kehl, 2004, p. 65).

O termo narcisismo tem o seu nome derivado de Narciso, e ambos derivam da palavra grega narké, que significa torpor, entorpecimento (Cunha, 1986, p. 544), mesma raiz etimológica da palavra narcótico. De certa maneira, o que verificamos no filme da Honda é um momento narcotizante em que vivem seus diversos personagens, estado de torpor que é, ao mesmo tempo, tradução do mito para a linguagem audiovisual e a tradução do 
prazer e da felicidade que a posse do produto proporciona. Estado de torpor proposto ao espectador, já imerso em uma realidade iconofágica, mundo repleto de imagens publicitárias velozes, que competem pelo olhar do consumidor, imagens devoradoras. De qualquer forma,

Junto com carros, cervejas e cartões de crédito acessíveis a uma parcela da sociedade, a publicidade vende sonhos, ideais, atitudes e valores para a sociedade inteira. Mesmo quem não consome nenhum dos objetos alardeados pela publicidade, como se fossem a chave da felicidade, consome a imagem deles. Consome o desejo de possuílos. Consome a identificação com o "bem", com o ideal de vida que eles supostamente representam. (Bucci e Kehl, 2004, p. 61)

Apesar de toda a complexidade que o filme analisado provoca, a criação em torno do mito de Narciso não é novidade. Severiano (2006) destaca o domínio da natureza como um dos mais fortes apelos da publicidade de carros: "Aqui se observam produtos de alta tecnologia da indústria automobilística, os quais possibilitam um domínio cada vez maior sobre o tempo/espaço, assim como estimulam à superação de obstáculos e à possibilidade de enfrentamento dos desafios naturais" (p. 116).

Curiosamente, o segmento automobilístico parece inerente ao que podemos chamar de "narcisismo midiático", pois toda a criação publicitária para automóveis traz como paradigmas sentidos relacionados à vaidade, à sexualidade masculina, à afirmação do ego, à beleza, à paixão, à aceitação social, ao hedonismo, ao poder — já que superar os desafios da natureza é uma indicação de potência-.

A imagem é a visão da completude e da onipotência. Não mais a visão de si próprio, mas a de um automóvel, agora representante da imagem ideal, do ego ideal, completo e perfeito, representativo da criança gloriosa que deixou de existir. A fusão se faz total: homem e objeto contemplamse, sendo este último seu "mais belo" reflexo (Severiano, 2006, p. 117).

\section{Conclusões}

Hoje, de qualquer maneira, constatamos que Narciso gosta mesmo é de ir às compras, sendo sua figura diluída na esfera do consumo. Porém, Narciso 
não está apenas no filme da Honda; ele está presente em todas e irrestritas formas de olhar para o outro, mesmo que mediado pelas imagens. A publicidade, de um modo geral, instiga a busca pela satisfação, pela felicidade. Conforme Pinheiro (2006),

Ao enunciar objetos de desejo [o produto em si ou a própria imagem de si], a publicidade apresenta também possíveis formas de desejar. Em geral, o desejo é apresentado como a busca daquilo que falta ao sujeito, mas, às vezes, aparece como potência, isto é, como força alegre do sujeito que é canalizada em algum alvo. (p. 171)

Assim, levando ao desejo, a publicidade leva à contemplação. Sua ordem é: observe o que te ofereço, encontre aqui você mesmo, o seu reflexo, encontre aqui a sua felicidade. No entanto, o que ela oferece é real? Para provocar reflexões, ao longo de suas observações em A felicidade paradoxal, Lipovetsky (2007) nos interpela: o consumo traz felicidade? Nesse percurso, o resultado foi o efetivo diálogo entre teorias que, na sua heterogeneidade, embasam as considerações acerca da felicidade inscrita e incitada no/pelo consumo por meio da publicidade.

\section{Referências}

Baitello Junior, N. (2005). A era da iconofagia: ensaios de comunicação e cultura. São Paulo: Hacker Editores.

Blikstein, I. (15 ago. 2008). Semiótica e comunicação. Palestra apresentada no VI Selisigno - Seminário de Estudos sobre Linguagem e Significação. Universidade Estadual de Londrina, Londrina.

Bucci, E. e Kehl, M. R. (2004). Videologias. São Paulo: Boitempo.

Camargo, H. W. de. (2013). Mito e filme publicitário: estruturas de significação. Londrina: Editora da Universidade Estadual de Londrina.

Costa Val, M. da G. (1999). Redação e Textualidade. São Paulo: Martins Fontes. 
Cunha, A. G. da. (1986). Dicionário Etimológico Nova Fronteira da Língua Portuguesa. Rio de Janeiro: Nova Fronteira.

F/Nazca. (2011).Narcisos. DOI: www.fnazca.com.br/index.php/2011/02/27/ narcisos/. [Citado em: 20 jan. 2016].

Koch, I. G. V. (1998). O texto e a construção dos sentidos. São Paulo: Contexto.

Koch, I. G. V. e Travaglia, L. C. (2003). A Coerência Textual. 15. ed. São Paulo: Contexto.

Koch, I. G. V. e Travaglia, L. C. (2005). Texto e Coerência. São Paulo: Cortez.

Kristeva, J. (2005). Introdução à Semanálise. São Paulo: Perspectiva.

Kury, M. da G. (2008). Dicionário de mitologia grega e romana. 8. ed. Rio de Janeiro: Jorge Zahar.

Lipovetsky, G. (2007). A felicidade paradoxal: ensaio sobre a sociedade de hiperconsumo. Trad. Maria Lúcia Machado. São Paulo: Companhia das Letras.

Lowen, A. (1989). Narcisismo: negação do verdadeiro "self". São Paulo: Círculo do Livro.

Noé, S. V. (2002 ago.). Homo Narcissicus. Numen: revista de estudos e pesquisa da religião, 5(1), 41-59.

Pinheiro, M. C. T. (2006 nov.). Publicidade: a procura amorosa do consumo. Comunicação, Mídia e Consumo, 3(8), 169-187. DOI: http:// dx.doi.org/10.18568/1983-7070.38169-187 
Rocha, E. (2006). Representações do consumo: estudos sobre a narrativa publicitária. Rio de Janeiro: Editora da Pontifícia Universidade Católica do Rio de Janeiro e Mauad.

Severiano, M. de F. V. (2006 nov.). Pseudo-individuação e homogeneização na cultura do consumo: reflexões críticas sobre as subjetividades contemporâneas na publicidade. Estudos e Pesquisa em Psicologia, 6(2), 105-121. DOI: http://www.revispsi.uerj.br/v6n2/artigos/ pdf/v6n2a09.pdf.

Sodré, M. (1994). A máquina de Narciso: televisão, indivíduo e poder no Brasil. São Paulo: Cortez Editora.

Tap, P. (1996). A sociedade pigmalião: integração social e a realização da pessoa. Trad. Clementina Nogueira. Lisboa: Instituto Piaget.

TotallyHistory. (2016). Narcissus. Recuperado em http://totallyhistory. com/narcissus/. [Citado em: 24 jan. 2016].

Vainer, P. (2011). Narcisos. [Filme publicitário]. F/Nazca. DOI: https:// www.youtube.com/watch?v=3dB9kIhEgSM 